\title{
Impact of the 'Repositioning Test' on Postoperative Outcome of Retroluminar Transobturator Male Sling Implantation
}

\author{
Ricarda M. Bauer ${ }^{\mathrm{a}}$ Christian Gozzi $^{\mathrm{c}} \quad$ Alexander Roosen $^{\mathrm{a}}$ Wael Khoder ${ }^{\mathrm{a}}$ \\ Matthias Trottmann $^{a}$ Raphaela Waidelich ${ }^{a}$ Christian G. Stief ${ }^{a} \quad$ Irina Soljanik $^{b}$ \\ ${ }^{a}$ Department of Urology, Ludwig Maximilian University, Munich, and ${ }^{b}$ Department of Neurourology, Spinal Cord \\ Injury Center, Heidelberg University Hospital, Heidelberg, Germany; ' ${ }^{\mathrm{C} D e p a r t m e n t}$ of Urology, Health Agency of \\ South Tyrol, Bressanone, Italy
}

\section{Key Words}

Retroluminar transobturator male sling $\cdot$ Repositioning test $\cdot$ AdVance sling $\cdot$ Postprostatectomy stress urinary incontinence Preoperative patient selection

\begin{abstract}
Objective: To evaluate prospectively the value of the 'repositioning test' (RT) in preoperative patient selection for the efficacy of male stress urinary incontinence (SUI) treatment using a retroluminar transobturator male sling (AdVance sling). Patients and Methods: 65 consecutive patients with SUl after radical prostatectomy were included in this singlecenter prospective study. Preoperatively, patients were classified into those with 'positive' and 'negative' RT. Postoperative results were analyzed and the association between the result of the RT and postoperative outcome was evaluated. Results: 53 patients $(81.5 \%)$ showed preoperatively a positive RT and 12 patients (18.5\%) a negative RT. After a followup of 12 months, patients with positive RT showed a cure rate (0 pads/day) of $83 \%$ and patients with a negative RT showed only a cure rate of $25 \%$. A positive RT significantly correlated with cure in outcome $(p<0.001)$. Conclusions:
\end{abstract}

Patients with positive RT have a significantly better chance for successful AdVance sling implantation. The RT is minimally invasive, easy to learn and easy to perform. Therefore, the RT is a very useful tool for preoperative patient selection.

Copyright $\odot 2013$ S. Karger AG, Basel

\section{Introduction}

Male slings are a surgical treatment option for persistent postprostatectomy stress urinary incontinence (SUI) $[1,2]$. The AdVance sling (American Medical Systems, Minnetonka, Minnesota, USA) is one of these male sling systems. It offers a non-compressive functional approach due to repositioning of the descended posterior urethra after prostate surgery [3]. In several studies the effectiveness and safety of the AdVance sling was shown [4-8]. However, the reported failure rate after AdVance sling implantation is $20-40 \%$ [1]. In recent years, several risk factors for failure of the AdVance sling were analyzed [9, 10]. A sufficient sling fixation and good residual sphincter function seem to have a positive impact on outcome. The inventors of the AdVance sling developed the so-

\section{KARGER}

E-Mail karger@karger.com

www.karger.com/uin
(C) 2013 S. Karger AG, Basel

0042-1138/13/0903-0334\$38.00/0
Ricarda M. Bauer, MD

Department of Urology, University Hospital Grosshadern Ludwig Maximilian University

Marchioninistrasse 15, DE-81377 Munich (Germany)

E-Mail ricarda.bauer@med.uni-muenchen.de 
called 'repositioning test' (RT) for empirical evaluation of the sphincter function in men with SUI before sling implantation. However, no studies evaluating the value of this test exist.

The aim of our study was to evaluate prospectively the value of the RT in the preoperative patient selection for the urological daily routine and the impact of this test on postoperative outcome.

\section{Patients and Methods}

Sixty-five consecutive male patients with persistent mild to severe SUI after radical prostatectomy were included in this singlecenter prospective, sequential clinical study and were treated with a retrourethral transobturator sling (AdVance sling). Inclusion and exclusion criteria for sling implantation were defined as previously reported [11]. To exclude any influence of other potential risk factors for failure, patients with previous incontinence surgery, neurological disorders or irradiated patients were additionally excluded from the study. In addition, sling arms were tunneled subcutaneously during implantation and 5 stitches with non-resorbable sutures were used to attach the sling on the bulb in order to reduce a failure rate $[9,10]$.

Before sling implantation, all patients had an intensive workup including: urethroscopy including the RT, evaluation of daily pad usage, 1-hour pad test, uroflowmetry, ultrasound for residual urine volume, and urodynamic assessment to exclude detrusor overactivity. Sling implantation was performed by two experienced surgeons ( $>50$ procedures). The surgical technique for implantation of the AdVance sling has been previously described [11]. Follow-up was performed in a standardized procedure by an independent physician - not one of the surgeons. Three and 12 months after sling implantation a re-evaluation of the patients was performed including ultrasound for residual urine volume, uroflowmetry, evaluation of daily pad use, 1-hour pad test and evaluation of the PGI-I (Patient Global Impression of Improvement). No patient was lost to follow-up. Informed consent from all patients and ethical approval from the local ethics committee were obtained.

\section{Repositioning Test}

The RT is performed during urethroscopy in the lithotomy position of the awake patient. The goal of the RT is to relocate the posterior urethra $2-3 \mathrm{~cm}$ proximally. A $0^{\circ}$ cystoscope is positioned distally of the sphincter region with a view on the whole circumference of the external urinary sphincter. Repositioning of the posterior urethra is performed by applying a gentle midperineal pressure parallel to the anal canal (midway between scrotum and anus) and below the bulbar urethra. The RT is assessed at rest and during voluntary contraction of the pelvic floor of the patient. The test is positive if the sphincter closes autonomous, in a reflex and concentric manner with complete closure during repositioning of the posterior urethra and if the functional urethra showed a lengthening by $\geq 1 \mathrm{~cm}$ (= coaptive zone) during active sphincter contraction (fig. 1). The length of the coaptive zone was measured visually by a marked cystoscope. If the coaptive zone is $<1 \mathrm{~cm}$ the RT is negative (fig. 2).
The RT was performed in the first 20 patients by two physicians independently. The results were the same in all cases, therefore in the next patients the test was performed only by one of them.

\section{Statistics}

For statistical analysis, the software SPSS Statistics (SPSS 17.0; SPSS Inc., Chicago, Ill., USA) was used. The pre- and postoperative comparison of pads per day, pad weight, uroflowmetry and PVR was performed with the Wilcoxon signed rank test. The comparison of patients with positive and negative RT was performed with the Mann-Whitney $U$ test. $p$ values $<0.05$ were regarded as significant. Cure was defined as 0 pads/day. All other patients were defined as 'not cured'. Physicians performing the follow-up visit were blinded to the result of the RT.

\section{Results}

Preoperative patients' characteristics are listed in table 1. Preoperatively, $53(81.5 \%)$ patients showed a positive and $12(18.5 \%)$ patients a negative RT. After a followup of 12 months, overall cure rate was $70.8 \%(\mathrm{n}=46)$. Patients with positive RT showed a cure rate of $83 \%$ ( $\mathrm{n}=$ $44)$ and a failure rate of $17 \%(n=9)$. In contrast, patients with negative RT had a cure rate of $25 \%(\mathrm{n}=3)$ and $75 \%$ $(\mathrm{n}=9)$ were not cured.

At 12 months' follow-up, mean PGI-I was 1.63 in all patients, 1.4 in those with positive test, and 2.85 in those with negative RT $(\mathrm{p}>0.001)$. A positive RT and cure in the outcome correlated significantly $(\mathrm{p}<0.001)$. There was no significant correlation between incontinence severity and the result of the RT $(\mathrm{p}=0.091)$. Daily pad usage and urine loss in the 1-hour pad test decreased significantly (median from 4.6 to 0.9 pads/day and from 104.3 to $26.6 \mathrm{~g} /$ day; both $<0.001$ ). Between 3 and 12 months' follow-up, no worsening over time was noticed ( $\mathrm{p}=$ 0.283). No intraoperative complications occurred.

Postoperatively, $13.8 \%$ of the patients $(n=9)$ experienced a transient urinary retention or residual urine $>200 \mathrm{ml}$ and were treated with a suprapubic catheter for a maximum of 8 weeks (range 6 days to 8 weeks, median 23 days). As soon as the residual urine was below $50 \mathrm{ml}$ the suprapubic catheter was removed. No further treatment for urinary retention/residual urine was necessary. There was no statistical difference in patients with negative or positive RT ( $\mathrm{p}=0.641)$. No severe early or later complications like worsening of incontinence, infection, persistent pain, sling erosion, sling dislocation or sling explantation occurred. 

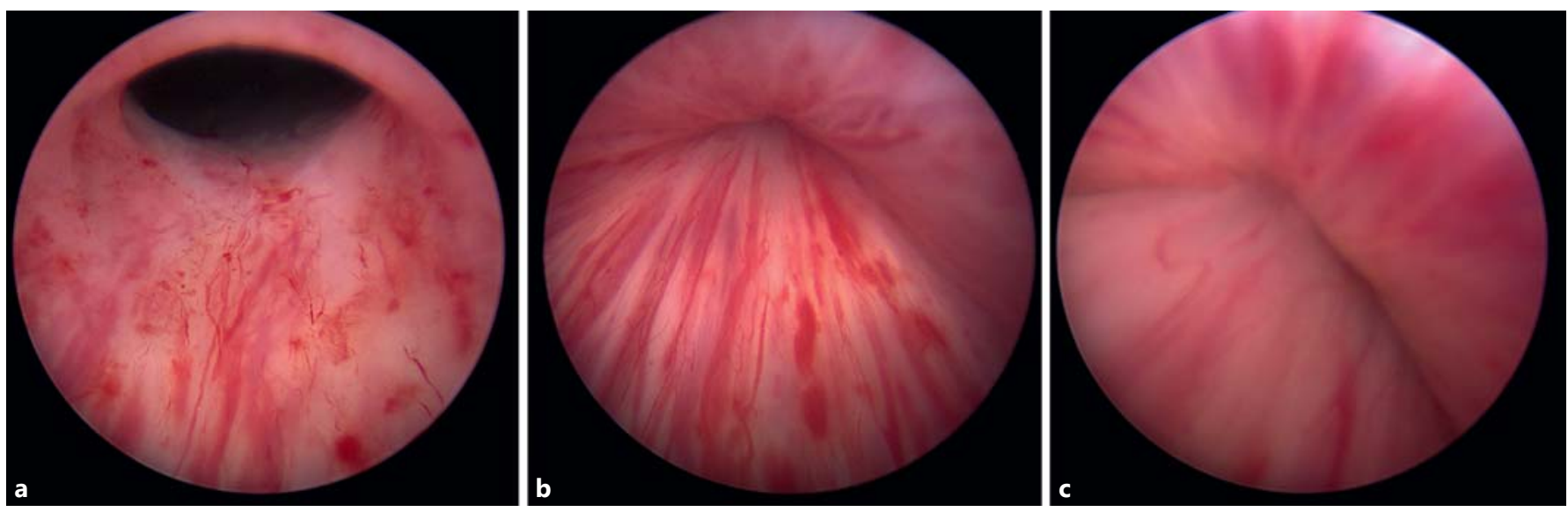

Fig. 1. Positive RT. a Before repositioning. b During repositioning without active sphincter contraction. c During repositioning with active sphincter contraction.
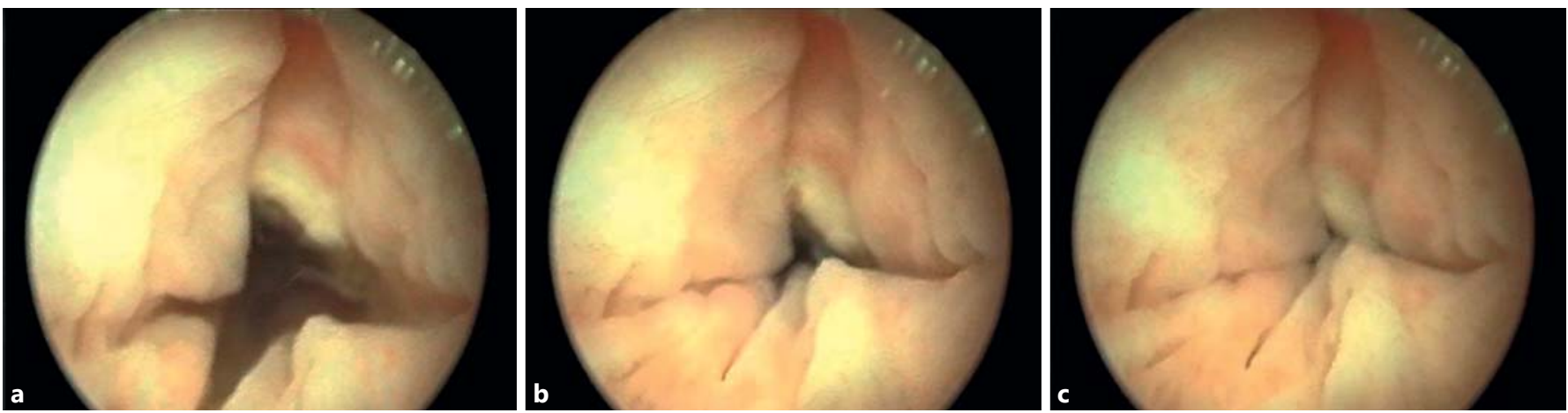

Fig. 2. Negative RT. a Before repositioning. b During repositioning without active sphincter contraction. c During repositioning with active sphincter contraction.

Table 1. Preoperative patients' characteristics $(n=65)$

\begin{tabular}{ll}
\hline $\begin{array}{l}\text { Age at sling } \\
\text { implantation }\end{array}$ & $\begin{array}{l}55-80 \text { years } \\
\text { median } 69.5 \text { years } \\
\text { mean } 69.7 \text { years }\end{array}$ \\
\hline $\begin{array}{l}\text { Daily pad } \\
\text { usage }\end{array}$ & $\begin{array}{l}1-16 \text { pads/day } \\
\text { median } 4.6 \\
\text { mean } 4.9\end{array}$ \\
\hline $\begin{array}{l}\text { Urine loss in } \\
\text { 1-hour pad test }\end{array}$ & $\begin{array}{l}12-387 \mathrm{~g} \\
\text { median } 104.3 \mathrm{~g} \\
\text { mean } 117.1 \mathrm{~g}\end{array}$ \\
\hline $\begin{array}{l}\text { Grade of } \\
\text { incontinence }\end{array}$ & $\begin{array}{l}\text { mild }(1-2 \text { pads/day): } 11 \text { patients }(16.9 \%) \\
\text { moderate }(3-5 \text { pads/day): } 36 \text { patients }(55.4 \%)\end{array}$ \\
& severe ( $\geq 6$ pads/day): 18 patients $(27.7 \%)$ \\
\hline
\end{tabular}

\section{Discussion}

Several potential risk factors for failure after AdVance sling implantation are hypothesized. In a multivariate analysis of potential risk factors weak residual sphincter function and an incomplete closure of the sphincter, no elongation of the coaptive sphincter zone, no sling tunneling and use of resorbable sutures with a small number of stitches were detected as significant predictors for sling failure [10]. In addition, a coaptive zone of at least 5-10 $\mathrm{mm}$ was presumed as a precondition for success [9]. The inventors of the AdVance sling recommend the evaluation of the coaptive zone before sling placement by repositioning of the membranous urethra during urethroscopy using the so-called RT. However, the impact of this test on successful sling outcome has not been evaluated yet.

Bauer/Gozzi/Roosen/Khoder/ Trottmann/Waidelich/Stief/Soljanik 
In the present study, data from 65 patients treated with the AdVance sling due to mild to severe SUI after radical prostatectomy were analyzed by classifying the patients with positive and negative RT. Six months after sling implantation, patients with positive RT showed significantly higher cure rate in contrast to patients with negative RT.

Among different surgical approaches developed to treat male SUI, the choice of the method depends on the mode of action. The majority of surgical procedures act in a compressive manner on the urethral lumen. The AdVance sling was described to have a 'functional' effect by relocation the membranous urethra with the sphincteric complex proximally $[4,8]$. This mechanism is based on the assumption that due to radical prostatectomy the sphincteric support can loosen with descent of the membranous urethra including the external urinary sphincter $[2,8]$. Thus, success of the AdVance sling is only possible if the external urinary sphincter is intact and only sphincteric support is injured with the result of sphincter hypermobility. Considering the knowledge of multifactorial SUI origin [11], the preoperative patient selection becomes important to achieve optimal results after AdVance sling implantation. The goal of the preoperative selection is to differentiate patients with 'intrinsic' deficiency of the external urinary sphincter from those with hypermobility of the sphincter but intact sphincter function. However, existing diagnostic procedures like videourodynamics have a limited value in predicting sphincter function and AdVance sling outcome. Therefore, no diagnostic procedures are actually available for urologists in daily practice to evaluate preoperatively the external urinary sphincter function. In our study, a positive RT correlated with a high cure rate in the outcome after AdVance sling implantation.

This test is minimally invasive, not time-consuming, easy to perform and easy to learn as well as it does not make additional diagnostic procedures necessary because preoperative urethroscopy is already a recommended assessment before male SUI surgery. The RT is able to assess only qualitatively the external urinary sphincter function and this may be a limitation of more exact cure rate prediction after AdVance sling. Furthermore, it is not useful for prediction of other SUI reasons and should be considered only as a part of complex preoperative diagnostics. In addition, the RT may not be reliable for quantitative assessment of the degree to that the membranous urethra has to be relocated for continence regaining during sling implantation. This may be a reason for $17 \%$ of patients with positive RT who failed after AdVance sling implantation.
Limitation of the study is the follow-up period of only 12 months. However, no other published study exists evaluating the impact of the RT in the preoperative patients' selection on postoperative success of the AdVance sling. With regard to significant correlation with a high cure rate after AdVance sling, we consider the RT as an important tool for the urologist in the preoperative diagnostic enabling better patient selection and success in the AdVance sling outcome.

\section{Conclusions}

Patients with positive RT have a significantly better chance for successful AdVance sling implantation. The RT is minimally invasive, easy to learn and easy to perform. Therefore, the RT is a very useful tool for preoperative patient selection and can be recommended in urological daily practice.

\section{Disclosure Statement}

R.M.B. declares lectures and consultancy work for AMS. C.G. holds the intellectual property as a co-inventor of the procedure. C.G. declares consultancy work, lectures, and participation in clinical trials for AMS. All authors declare that no funding or other agreement has limited their ability to fairly complete and publish these data and they had full control of the primary data. There has been no extra-institutional funding for this study.

References
Bauer RM, Gozzi C, Hubner W, Nitti VW, Novara G, Peterson A, Sandhu JS, Stief CG: Contemporary management of postprostatectomy incontinence. Eur Urol 2011;59:985996.

2 Thuroff JW, Abrams P, Andersson KE, Artibani W, Chapple CR, Drake MJ, Hampel C, Neisius A, Schroder A, Tubaro A: EAU guidelines on urinary incontinence. Eur Urol 2011; 59:387-400.

3 Gozzi C, Becker AJ, Bauer R, Bastian PJ: Early results of transobturator sling suspension for male urinary incontinence following radical prostatectomy. Eur Urol 2008;54:960-961.

-4 Bauer RM, Mayer ME, May F, Gratzke C, Buchner A, Soljanik I, Bastian PJ, Stief CG, Gozzi C: Complications of the AdVance transobturator male sling in the treatment of male stress urinary incontinence. Urology 2010;75:1494-1498. 
5 Bauer RM, Soljanik I, Fullhase C, Buchner A, May F, Stief CG, Gozzi C: Results of the AdVance transobturator male sling after radical prostatectomy and adjuvant radiotherapy. Urology 2011;77:474-479.

6 Cornu JN, Sebe P, Ciofu C, Peyrat L, Cussenot $\mathrm{O}$, Haab F: Mid-term evaluation of the transobturator male sling for post-prostatectomy incontinence: focus on prognostic factors. BJU Int 2011;108:236-240.
Rehder P, Haab F, Cornu JN, Gozzi C, Bauer RM: Treatment of postprostatectomy male urinary incontinence with the transobturator retroluminal repositioning sling suspension: 3-year follow-up. Eur Urol 2012;62:140-145.

8 Rehder P, Mitterberger MJ, Pichler R, Kerschbaumer A, Glodny B: The 1-year outcome of the transobturator retroluminal repositioning sling in the treatment of male stress urinary incontinence. BJU Int 2010;106:16681672.

-9 Rehder P, Freiin Von Gleissenthall G, Pichler R, Glodny B: The treatment of postprostatectomy incontinence with the retroluminal transobturator repositioning sling (AdVance): lessons learnt from accumulative experience (in Spanish). Arch Esp Urol 2009; 62:860-870.
10 Soljanik I, Gozzi C, Becker AJ, Stief CG, Bauer RM: Risk factors of treatment failure after retrourethral transobturator male sling. World J Urol 2012;30:201-206.

11 Bauer RM, Mayer ME, Gratzke C, Soljanik I, Buchner A, Bastian PJ, Stief CG, Gozzi C: Prospective evaluation of the functional sling suspension for male postprostatectomy stress urinary incontinence: results after 1 year. Eur Urol 2009;56:928-933. 